\title{
Pilihan Bahasa Anak Jalanan Penjual Koran di Kawasan Tugu Muda Semarang
}

\author{
Febrian Kurniaji ${ }^{\bowtie}$, Tommi Yuniawan, Ahmad Syaifudin
}

Jurusan Bahasa dan Sastra Indonesia, Fakultas Bahasa dan Seni, Universitas Negeri Semarang, Indonesia

\section{Info Artikel}

Sejarah Artikel:

Diterima April 2018

Disetujui Mei 2018

Dipublikasikan Juli 2018

\section{Keywords:}

language choice; speech

events; street children

newspaper sellers

\begin{abstract}
Abstrak
Tujuan penelitian ini adalah mengetahui pilihan bahasa anak jalanan penjual koran di kawasan Tugu Muda Semarang. Penelitian ini menggunakan metode penelitian kualitatif dengan teknik pengumpulan data bebas libat cakap. Metode analisis data yang diperoleh dengan analisis model intraktif. Hasil penelitian, ditemukan bahwa wujud pilihan bahasa anak jalanan penjual koran di kawasan Tugu Muda Semarang adalah tuturan bahasa Jawa ragam ngoko lugu dan ngoko alus serta bahasa Indonesia ragam Informal. Selain itu ditemukan juga pilihan bahasa anak jalanan penjual koran dalam wujud bahasa Indonesia dan bahasa Jawa berupa tunggal bahasa, alih kode, dan campur kode. Tuturan tersebut dipengaruhi oleh faktor latar [waktu dan tempat) dan situasi, faktor partisipan dalam interaksi, faktor percakapan, dan faktor fungsi interaksi. Pada penelitian ini ditemukan pilihan bahasa anak jalanan penjual koran didominasi oleh bahasa Jawa. Anak jalanan penjual koran sebaiknya selektif dalam memilih kosakata dan ragam bahasa Jawa ketika bertutur, agar nilai anak jalanan penjual koran mempunyai nilai yang baik dan sopan di mata masyarakat umum.
\end{abstract}

\section{Abstract}

The aim this research it to know the language chosen by street boys who sell newspaper in the area of Tugu Muda Semarang. The method of this research is qualitative by using the technique of data simak libat cakap and simak bebas libat cakap. The method of data analysis that has been gotten with the analysis of interactive model. The resultof this research, found out that shape the language that has been chosen by the strees boys who sell newspaper in the area Tugu Muda Semarang is the Javanese speech that is ngoko lugu and ngoko alus the informal of Indonesian speech. Besides, it was also found that the chosen of the language of the street boys who sell newspaper in the Indonesian language and Javanese language in the form of single language, code switching, and code mixing. The speech influenced by the background factor (time and place) and situation, the participants factor in the interaction, speech factor, and the factor of the language of the street boys who sell newspaper dominate by Javanese language. The street boys who sell newspaper it is better to be selective in choosing vocabulary and Javanese language's diversity when saying, so the value of the street boys have a good value and have well mannered in the eye of the society.

(C) 2018 Universitas Negeri Semarang

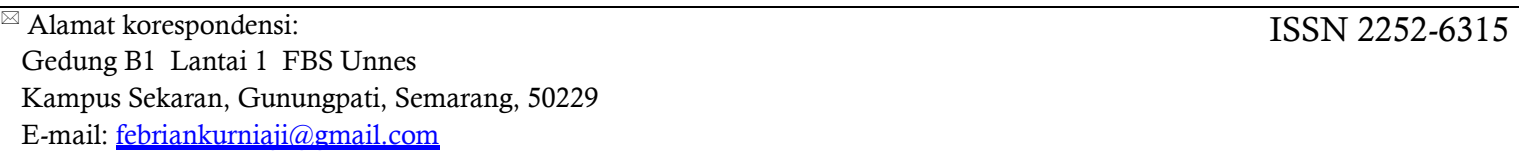




\section{PENDAHULUAN}

Pilihan bahasa menurut Fasold (dalam Chaer dan Agustina 2010:153) yaitu masyarakat bilingual atau multilingual berbicara dua bahasa atau lebih dan memilih mana yang harus digunakan. Ada tiga jenis pilihan yang dapat dilakukan, yaitu, pertama alih kode, campur kode, dan memilih variasi bahasa yang sama. Menurut Evin-Trip (dalam Fathur Rokhman 2013:26) pilihan bahasa dipengaruhi oleh faktor (1) latar (waktu dan tempat) dan situasi; (2) partisipan dalam interaksi, (3) topik percakapan, dan (4) fungsi interaksi.

Dalam masyarakat Indonesia yang multibahasa, pilihan bahasa merupakan masalah yang kompleks. Pada situasi kebahasaan seperti itu terdapat beberapa bahasa yang hidup berdampingan dan digunakan dalam interaksi sosial. Setiap anggota masyarakat mau tidak mau harus memilih bahasa atau ragam bahasa untuk digunakan dalam interaksi tertentu. Salah satu keragaman yang muncul di masyarakat di antaranya adalah bahasa anak-anak jalanan di kawasan tugu muda Semarang. Anak jalanan tersebut menggunakan pilihan bahasa saat menawarkan daganganya. Gejala yang menarik untuk diketahui bagaimana bahasa-bahasa yang berbeda itu dipilih dalam setiap kesempatan komunikasi yang ada. Ada faktor yang memengaruhi pilihan bahasa yang mereka gunakan ketika berkomunikasi dengan masyarakat dari berbagai golongan, mulai dari ekonomi menengah ke bawah hingga ekonomi atas.

\section{METODE PENELITIAN}

Pendekatan dalam penelitian ini menggunakan pendekatan teoretis dan penedekatan secara metodologis. Pendekatan teoretis pada penelitian ini berupa pendekatan sosiolinguistik. Pendekatan sosiolinguistik digunakan dalam penelitian ini untuk menganlisis penggunaan bahasa pada anak jalanan penjual koran. Pendekatan metodologis yang digunakan pada penelitian ini adalah pendekatan deskriptif kualitatif. Menurut Moloeng (2012:11), pendekatan deskriptif kualitatif adalah data yang dikumpulkan berupa kata-kata, gambar, dan bukan angka-angka. Selain itu, semua yang dikumpulkan berkemungkingan menjadi kunci terhadap apa yang sudah diteliti. Dengan demikian, laporan penelitian akan berisi kutipan-kutipan data untuk memberi gambaran penyajian laporan tersebut. Pendekatan deskriptif kualitatif digunakan dalam penelitian ini karena penelitian ini menghasilkan data deskriptif berupa tuturan bahasa Jawa dan bahasa Indonesia pada anak jalanan penjual koran.

\section{HASIL PENELITIAN DAN PEMBAHASAN}

Wujud pilihan bahasa anak jalanan penjual koran di kawasan Tugu Muda Semarang meliputi:

\section{Tunggal Bahasa}

Memilih satu variasi bahasa dari bahasa yang sama (intra language variation). Apabila seorang penutur bahasa Jawa berbicara kepada orang lain dengan menggunakan bahasa Jawa kromo, misalnya, maka ia telah melakukan pilihan bahasa kategori pertama ini (Rokhman 2013:25).

Tunggal bahasa Jawa

KONTEKS : Ragam bahasa Jawa ngoko lugu. Anak jalanan sedang beribincang-bincang di kawasan Tugu muda Semarang

P1 : kowe pingin sepatu rodo [kowe pInIn səpatu rodo] 'kamu ingin sepatu roda?'

P2 : yo iki, aku pingin tuku [yo iki, aku pInIn tuku] 'ya saya ingin beli'

P1 : engko ibumu meh nukoke [əク?o ibumu meh nuks?e] 'nanti ibumu akan 
membelikan'

Data (6) merupakan wujud tunggal

(Data 2) bahasa Indonesia penjual koran di kawasan Tugu Muda Semarang. Hal tersebut dibuktikan

Tuturan pada data (2) merupakan wujud tunggal bahasa Jawa ragam ngoko lugu penjual koran di kawasan Tugu Muda Semarang. Hal tersebut dibuktikan dengan adanya penggunaan satu bahasa yaitu bahasa Jawa tanpa ada bahasa lain. Ragam bahasa Jawa yang digunakan dalam tuturan teresebut merupakan ragam ngoko lugu. Tuturan bahasa Jawa ragam ngoko lugu digunakan pada situasi santai dan mencerminkan keakraban antara penutur dan mitra tutur. Keakraban yang dimaksudkan merupakan keakraban hubungan antara teman sesama anak jalanan.

Sementara itu, ragam ngoko alus digunakan oleh anak jalanan untuk menarik minat beli koran. Ragam ngoko alus digunakan oleh anak jalanan agar terkesan lebih sopan. Ngoko alus adalah percampuran antara bahasa Jawa ngoko lugu dan krama alus atau krama lugu. Ragam ini digunakan oleh peserta tutur untuk saling menghormati pada lawan tutur (Hardyanto dan Utami dalam Sukoyo 2013:14). Berikut wujud tuturan tunggal bahasa Jawa ragam ngoko alus.

\section{Tunggal bahasa Indonesia}

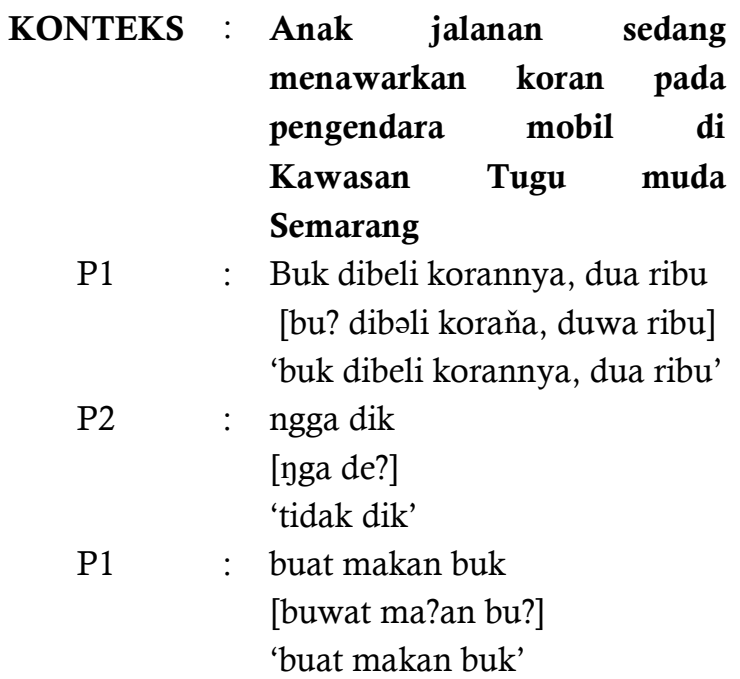

(Data 6) dengan adanya penggunaan satu bahasa yaitu bahasa Indonesia tanpa ada bahasa lain. Pilihan bahasa Indonesia digunakan oleh anak jalanan penjual koran disebabkan karena faktor partisipan dalam interaksi yang berhubungan dengan pendidikan. Sebagian besasr anak jalanan menempuh pendidikan. $\mathrm{Hal}$ itu menyebabkan mereka pandai menggunakan bahasa Indonesia dan bersikap sopan santun kepada orang yang lebih tua seperti yang diajarkan di sekolah.

Peristiwa tutur di atas terlihat adanya penggunaan bahasa Indonesia yang utuh dan tidak tersisipi oleh bahasa lain pada setiap tuturan. Hal itu membuktikan bahwa adanya penggunaan tunggal bahasa Indonesia oleh anak jalanan penjual koran di kawasan Tugu Muda Semarang. Penggunaan tunggal bahasa Indonesia digunakan oleh anak jalanan untuk menghormati pembeli yang menggunakan mobil karena dianggap mempuyai status sosial yang lebih tinggi.

\section{Alih Kode}

Appel (dalam Chaer dan gustina 2010: 107) mendefinisikan alih kode sebagai gejala peralihan pemakaian bahasa karena berubahnya situasi. Soewito (dalam Sumarsono 2010: 114) membedakan adanya dua macam alih kode, yaitu alih kode intern dan alih kode ekstern. Alih kode intern adalah alih kode yang berlangsung antarbahasa sendiri, seperti dari bahasa Indonesia ke bahasa Jawa, atau sebaliknya. Sedangkan alih kode ekstern terjadi antara bahasa sendiri dengan bahasa asing.

$\begin{array}{cll}\text { KONTEKS : } & \text { Pembeli menghampiri anak } \\ & \text { jalanan penjual koran di } \\ & \text { Kawasan Tugu Muda } \\ & \text { Semarang } \\ \text { P1 } \quad: \text { Dik beli korannya satu } & \text { [dI? boli koranň satu] } \\ & \text { 'Dik beli korannya satu' }\end{array}$




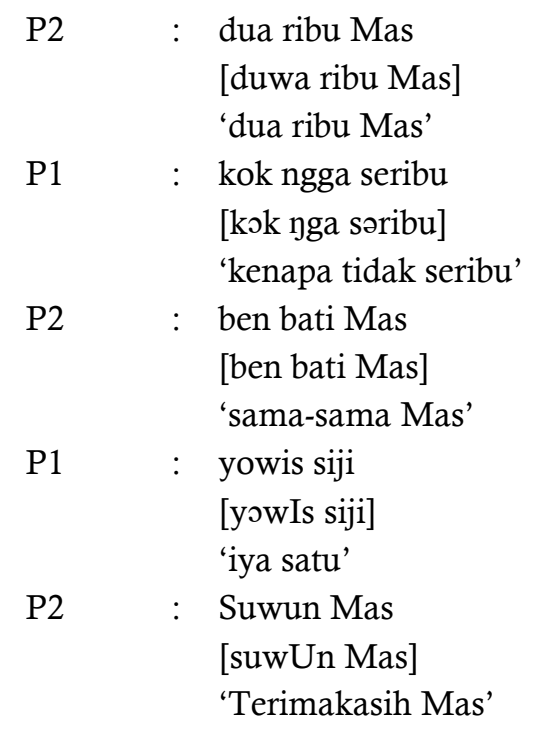

Peristiwa tutur di atas terjadi ketika melakukan transaksi jual beli di kawasan Tugu Muda Semarang. P1 pada peristiwa tutur di atas yaitu pembeli, sedangkan P2 yaitu anak jalanan penjual koran. Awalnya, P1 bertanya kepada P2 dengan menggunakan bahasa Indonesia "Dik beli korannya". Kemudian P2 menjawab dengan bahasa Indonesia pula "dua ribu Mas". P1 menanggapi dengan bahasa Indonesia "kok ngga seribu". Setelah itu, P2 tidak menjawab lagi dengan bahasa Indonesia, akan tetapi beralih dengan menggunakan bahasa Indonesia, "ben bati". Selanjutnya, P1 mengikuti beralih kode bahasa Jawa. Hal ini menunjukkan telah terjadi peralihan kode dari bahasa Indonesia ke bahasa Jawa. Hal ini dilakukan karena dinilai lebih komunikatif.

\section{Campur kode}

Campur kode adalah menggunakan satu bahasa tertentu dengan bercampur serpihanserpihan sari bahasa lain (Rokhman 2013: 26). Pada campur kode penutur menyisipkan unsurunsur bahasa lain ketika sedang memakai bahasa yang satu ke bahasa yang lain (Sumarsono 2010: 200).

KONTEKS : Anak jalanan menawarkan koran pada pembeli di Kawasan Tugu Muda Semarang

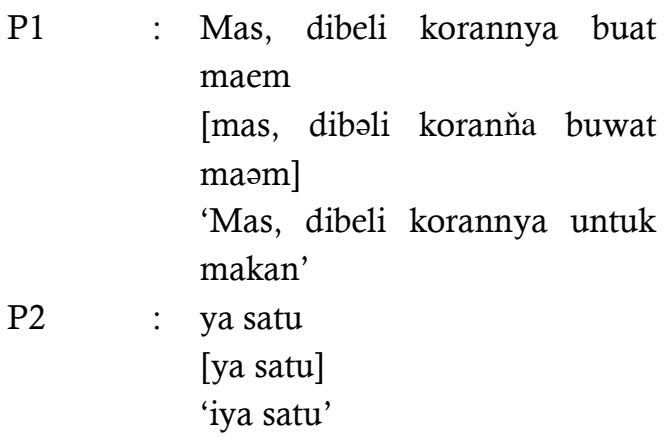

(Data 10)

Penggalan tuturan pada data (10) terjadi antara anak jalanan penjual koran P1 dan pembeli P2. Dalam penggalan tuturan tersebut terdapat campur kode bahasa Jawa ke dalam bahasa Indonesia. Campur kode tersebut dilakukan oleh anak jalanan P1. P1 melakukan campur kode bahasa Jawa ke dalam bahasa Indonesia pada tuturan 'Mas, dibeli korannya buat maem'. Tuturan 'Mas dibeli korannya buat' merupakan bahasa Indonesia, sedangkan 'maem' merupakan kosa kata bahasa Jawa. campur kode yang dilakukan oleh P1 dipengaruhi oleh situasi nonformal dan tujuan tuturan untuk menarik P2 agar membeli koran. Selain data di atas juga ditemukan campur kode antara bahasa bahasa Jawa dengan bahasa Indonesia dalam bentuk register. Berikut adalah wujud tuturan campur kode anak jalanan penjual koran di kawasan Tugu Muda Semarang dalam bentuk register bahasa Indonesia.

Faktor yang memengaruhi pilihan bahasa anak jalanan penjual koran di kawasan Tugu Muda Semarang

Wujud pilihan bahasa yang terjadi pada anak jalanan penjual koran di kawasan Tugu Muda Semarang dipengaruhi oleh beberapa faktor. Berikut beberapa faktor tersebut.

\section{Faktor latar (waktu dan tempat) dan situasi}

Situasi tutur memengaruhi kemunculan pilihan bahasa anak jalanan penjual koran di kawasan Tugu Muda Semarang. Situasi tersebut dapat berupa kekeluargaan, keakraban sesama anak jalanan, dan situasi jual beli. Adapun contoh pilihan bahasa yang dipengaruhi oleh 
situasi dapat dilihat pada penggalan tuturan berikut. Faktor keakraban santai.

\begin{tabular}{|c|c|}
\hline KONTEKS & $\begin{array}{l}\text { Anak jalanan penjual koran } \\
\text { sedang berbincang penda- } \\
\text { patan penjualan koran }\end{array}$ \\
\hline P1 & $\begin{array}{l}\text { kowe entuk piro? } \\
\text { [kowe entU? piro ] } \\
\text { 'kamu dapat berapa' }\end{array}$ \\
\hline $\mathrm{P} 2$ & $\begin{array}{l}\text { nembe sithik, soale udan iki } \\
\text { dhurung tak itung } \\
\text { [nəmbe sițI? soale udan iki } \\
\text { dUrUy ta? ItUn] } \\
\text { 'baru sedikit, soalnya hujan ini } \\
\text { baru saya hitung' }\end{array}$ \\
\hline P1 & $\begin{array}{l}\text { ditung cobo, kowe meh bali? } \\
\text { [dItUy cobo, kowe meh bali] } \\
\text { 'dihitung coba, kamu akan } \\
\text { pulang?' }\end{array}$ \\
\hline $\mathrm{P} 2$ & $\begin{array}{l}\text { selawe ewu thok ih, aku tak } \\
\text { balik sik ya } \\
\text { [səlawe \&wu thok ih, aku ta? } \\
\text { balI? sI? yo] } \\
\text { 'hanya dua puluh lima ribu, } \\
\text { saya akan pulang terlebih } \\
\text { dahulu' }\end{array}$ \\
\hline P1 & $\begin{array}{l}\text { : yo } \\
\text { [yo] } \\
\text { 'iya' }\end{array}$ \\
\hline
\end{tabular}

(Data 1)

Pada data (1) terjadi peristiwa tutur ketika anak jalanan sedang bercerita terkait pendapatan jualan koran. Situasi yang tergambar merupakan situasi santai, sehingga penutur melakukan ragam bahasa Jawa ngko lugu. Situasi santai yang mencerminkan keakraban sesama anak jalanan penjual koran seperti tuturan di atas menjadi faktor penyebab penggunan bahasa Jawa ragam ngoko lugu. Selain data di atas berikut tuturan anak jalanan yang memengaruhi situasi jual beli koran

\section{Faktor partisipan dalam interaksi}

Faktor partisipan dalam interaksi mencakup hal-hal seperti usia, jenis kelamin, pekerjaan, status sosial ekonomi, dan peranannya dalam hubungan dengan mitra tutur. Hubungan mitra tutur dapat berupa hubungan akrab dan berjarak. Terkait juga dengan tingkat pendidikan dan latar belakang etnis, serta hadirnya partisipan baru atau pihak ketiga juga akan memengaruhi bahasa yang sudah digunakan sebelumnya. Berikut adalah peristiwa tutur yang disebabkan oleh faktor partisipan yang berhubungan dengan usia.

\section{KONTEKS : Tuturan anak jalanan sedang menawarkan koran pada pembeli di Kawasan Tugu Muda \\ P1 : korane Mbak, ditumbas [ korane mba?, ditumbas] 'korannya Mbak, dibeli' \\ P2 : ya satu [ya satu] 'iya satu' \\ P1 : suwun $\mathrm{Mba}$ [suwUn mba? ] 'terimakasih mba'}

(Data 14)

Pada data (14) terjadi tuturan yang disebabkan oleh faktor penyebab partisipan dalam interaksi yang berhubungan dengan usia. Mitra tutur P2 memiliki usia yang lebih dewasa dibandingkan penutur P1. P1 berusaha menghormati P2, karena usianya lebih muda dan bersikap menghormati sehingga menyebabkan penggunaan bahasa Jawa ragam ngoko alus. Ragam bahasa jawa tersebut digunakan oleh anak jalanan penjual koran pada mitra tutur yang memiliki usia lebih dewasa.

\section{Faktor topik percakapan}

Faktor yang ketiga adalah topik percakapan. Topik yang diangkat dapat berupa tentang pekerjaan, keberhasilan anak, peristiwaperistiwa aktual, dan topik harga barang di pasar (Even-Trip dalam Rokhman 2013:27). 


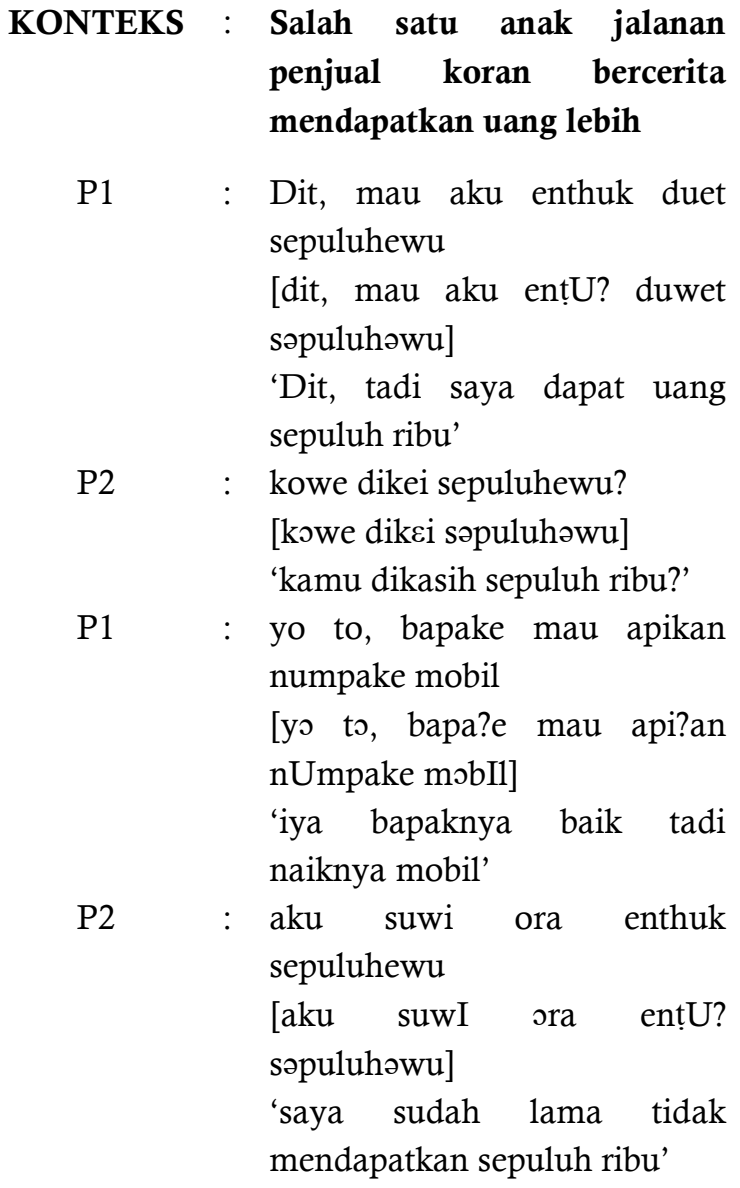

(Data 17)

Data (17) terjadi tuturan antar sesama anak jalanan penjual koran. Tuturan tersebut membahas topik pekerjaan mengenai salah satu anak jalanan mendapatkan uang sepuluh ribu dari hasil berjualan koran. Percakapan yang terjadi menggunakan bahasa Jawa ragam ngoko lugu. Berdasarkan analisis inilah, diketahui bahwa faktor penyebab terjadinya peristiwa tutur tunggal bahasa Jawa ragam ngoko lugu di atas adalah topik percakapan.

Faktor fungsi interaksi

\section{KONTEKS : Pembeli mencari tahu alasan anak jalanan berjualan koran di Kawasan Tugu Muda Semarang \\ P1 : kowe wis suwi dodol koran [kowe wIs suwI dodol koran] 'kamu sudah lama berjualan}

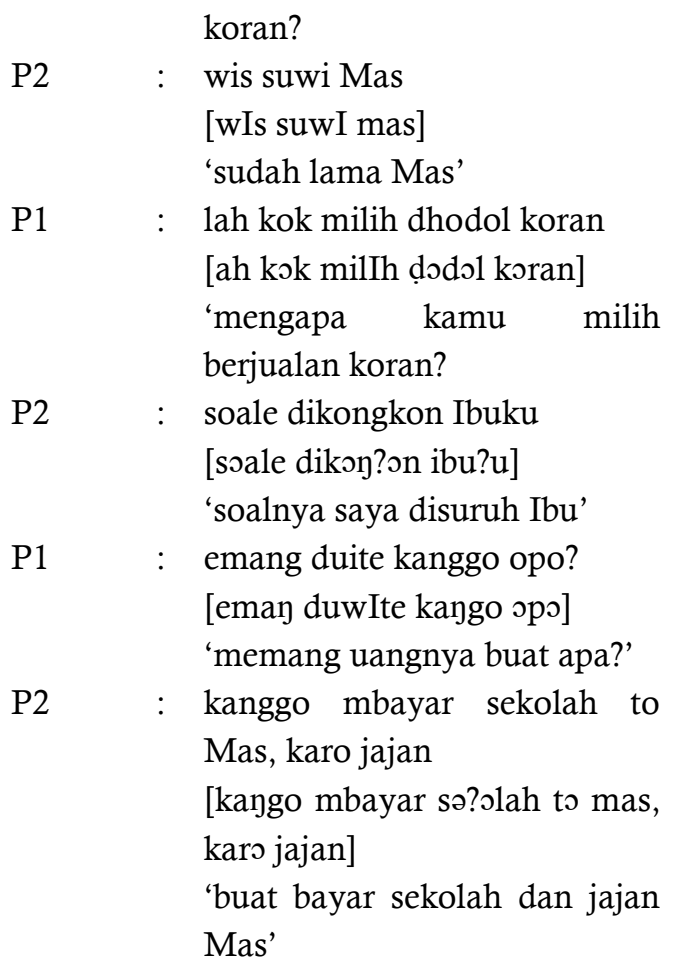

(Data 18)

Pada data (18) terjadi tuturan antara anak jalanan penjual koran P1 dan pembeli P2. P2 bertanya kepada anak jalanan mengenai alasan mereka berjualan koran di kawasan Tugu Muda. P1 menceritakan alasan mereka berjualan koran karena disuruh oleh ibu mereka. Selain itu, mereka bercerita walaupun berjualan koran tetapi tetap mengutamakan pendidikan. Sebagian uang hasil berjualan digunakan untuk biayaya sekolah mereka. Oleh sebab itu, P2 mendapatkan infomasi tentang alasan P2 berjualan koran di kawasan Tugu Semarang.

\section{SIMPULAN}

Berdasarkan hasil analisis data penelitian yang telah dilakukan, simpulan yang dapat dikemukakan adalah sebagai berikut:

Wujud pilihan bahasa Anak Jalanan penjual koran di kawasan Tugu Muda Semarang yaitu (a) variasi tunggal bahasa. Variasi tunggal bahasa berupa bahasa Jawa dan bahasa Indonesia. (b) Alih kode. Variasi alih kode berupa peralihan bahasa Indonesia ke bahasa Jawa. (c) Campur kode. Variasi campur kode 
yaitu campur kode antara bahasa Jawa dan bahasa Indonesia. Ditemukan juga kosa kata khusus yang menjadi register anak jalanan. Kosa kata khusus itu terbentuk dari peristiwa campur kode. Kosa kata khusus tersebut yaitu sikat.

Variasi dalam wujud pilihan bahasa anak jalanan penjual koran di kawasan Tugu Muda Semarang dipengaruhi oleh beberapa faktor : (a) latar (waktu dan tempat) dan situasi, (b) partisipan dalam interaksi yang meliputi (1) usia, (2) pendidikan, (3) jarak, dan (4) akrab, (c) topik percakapan, dan (d) fungsi interaksi.

\section{DAFTAR PUSTAKA}

Chaer, Abdul dan lonie Agustina. 2010. Sosiolingustik Perkenalan Awal. Edisi Revisi. Jakarta: Rineka Cipta

Moleong, Lexy J. 2012. Metodologi Penelitian Kualitatif. Bandung: PT Remaja Rosdakarya.

Rokhman, Fatur. 2013. Sosiolinguistik. Yogyakarta: Graha Ilmu

Sukoyo, Joko. 2013. Tentang Bahasa Jawa. Surakarta: Yuma Pustaka.

Sumarsono. 2013. Sosiolinguistik. Yogyakarta: Sabda dengan Pustaka Belajar. 